\section{Japan Boosts Basic Science}

Japan's parliament passed a Basic Science and Technology Law late last year requiring the government to do more to support basic research. It gave the country's science ministries and agencies considerable leverage in budget negotiations. For despite a continuing recession, they received large (5-10\%) increases in their budgets for 1996. There is a new Science and Technology Agency (STA) grant scheme for "strategic" research and a new Ministry of Trade and Industry (MITI) programme for "creative" research. So these agencies will be offering large grants to university scientists (a domain reserved up to now for the education ministry - whose grant budget also received a large boost). In line with the government's call to double the number of postdocs, the ministry and STA received large increases for postdoc fellowships, as did the STA's Centre of Excellence scheme for select groups of university scientists.

Akito Arima, professor of theoretical physics, former President of Tokyo University, and President of the Institute of Physical and Chemical Research (RIKEN), Wako, Saitama (which houses the new nextgeneration SPring- 8 synchrotron), is considered by many to be the driving force behind the new law. He also chairs the Central Council for Education which aims to reform Japan's educational system. Excepts from a recent interview by Gerhard Fasol summarise Professor Arima's views on the need for the investment in basic research.

-Why does Japan's research system need improvement?

"We need to emphasise basic science more ...... since we need to continuously improve our industries. However, today we have to buy many new technologies from abroad and this is very expensive. Therefore in the future we need to create more inventions."

- What is the background to the new Basic Science and Technology Law?

"In the 1980s the Japanese universities, especially the national universities, were not well treated by the national government; there was a 'minus ceiling policy' to reduce public expenditure. Every year we had $10 \%$ less to spend than the previous year's budget. After much lobbying, finally the politicians realised the importance of improving the universities and the national laboratories.

Industry also started to realise the importance of basic science for technology. Many managers think PhDs are useless for industry; they think that $\mathrm{PhDs}$ are too stubborn. Our industries want instead to hire very young Bachelors or Masters. But industry needs $\mathrm{PhDs}$ for the brain part of their research and their activities. Until today, Japanese industries were so strong because they had good competent engineers who are very good at learning and transferring new technologies from Europe or the USA. But from now on we will need our own brains...... You might be surprised at how small our number of $\mathrm{PhDs}$ is. It indicates that industry was more interested in applied technologies.

So we need to increase the number of $\mathrm{PhDs}$ by improving graduate schools and by asking industry and government to take as many $\mathrm{PhDs}$ as possible."
Akito Arima, President of RIKEN.

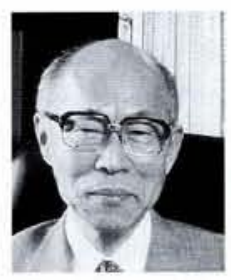

- But it is not only a question of numbers but a question of the style of $\mathrm{PhD}$ training. Don't you think that the PhD training is quite tight in some universities?

"Yes ..... in some faculties creative people still today might have trouble. In the graduate schools there are two things we must work on. The first is we should discover some very creative people But it is difficult. So rather than emphasizing how to educate these creative people we should create an atmosphere that encourages creativity. The second point is that we should educate the remaining excellent but not outstanding creative people into many competent $\mathrm{PhDs}$. One of my proposals is that we should introduce selectivity. Up to now equality has been much emphasized."

- How successful are big companies in managing basic research?

"The [industrial] basic research laboratories are always a kind of accessory. So companies have at least two laboratories: one is the central laboratory in which they study applied technologies, and then there is the further laboratory for basic science. But if the recession starts, the role of basic science is less encouraged. Contrary to industry, the universities are more stable; ...... [they] offer the potential stable conditions for basic science to thrive. But at the moment Japanese universities don't have so much venture spirit."

- What will be the fruits of the new law?

The new law has created the new atmosphere in Japan, where everybody thinks that basic science and technology is very important ..... already some budgets have been increased. We are already spending $3 \%$ of GNP on R\&D in Japan. However, only $20 \%$ comes from government - this is very small: in Germany it is $35 \%$ and in the USA this is almost $45 \%$. So government expenditure must increase.

To deliver the results now that our budgets have increased: this is our responsibility ! I feel a very strong responsibility to push for performance checks in our public research system. We need to 'activate' universities and national laboratories. So in order to activate them we need as much information as possible about individual institutes. Then this means that each research institute must publish a report with a self-evaluation of the research results. As a next step we must have at least peer-review. [Early ideas at the University of Tokyo and RIKEN] were not followed by others for many years. But now I am happy that first selfreviewing and then external reviewing have become a kind of fashion.

Reviewing of individual professors will come later. At the moment Japanese society is not ready for this. We are aiming for this, and in the near future we will also start evaluating individual researchers. In Japan we have so many universities (550) ...... and a very large number of national laboratories. So we must activate them. The best way to do that is by external reviewing. If we are too hasty we will create problems. We must carefully introduce evaluation systems."

\section{Energetic Cooperation}

The new President-Elect of the Physical Society of Japan, Professor Fumiko Yonezawa, is very well known in the international community of condensed matter physicists. She has done much to foster relations between Japanese physicists and their colleagues abroad, through conferences and workshops, such as the Taniguchi Symposium. Much of her research has been concerned with disordered solids, glasses and amorphous semiconductors. She was formerly at the Research Institute for Fundamental Physics, Kyoto University, and is now Professor at Keio University. We can look forward to a period of enhanced cooperation with the Physical Society of Japan under her energetic leadership. [D.L. Weaire, EPS President-Elect]

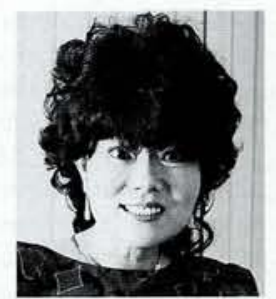

